\title{
Effects of Intrathecal and Intravenous Administration of Dexmedetomidine on Motor Function Recovery and Inflammatory Response in Rats with Spinal Cord Injury
}

Y. CHAI, SHUXIN WEI ${ }^{1}$, SHILI DU AND QING ZHAO ${ }^{*}$

Department of Anesthesiology, The First People's Hospital of Jinan City, Jinan, ${ }^{1}$ Department of Anesthesiology, The Sixth People's Hospital of Jinan City, Jinan, '2Department of Anesthesiology, The Second People's Hospital of Jinan City, Jinan, PR China

Chai et al.: Effects of Dexmedetomidine on Motor Function Recovery and Inflammatory Response in Rats

To analyze the effects of intrathecal and intravenous dexmedetomidine on motor function recovery and inflammatory response in rats with spinal cord injury. The rats were divided into three groups, the right femoral sheath injection group $(3 \mu \mathrm{g} / \mathrm{kg})$, the right femoral sheath injection $\mathrm{group}(3 \mu \mathrm{g} / \mathrm{kg})$ Dexmedetomidine $(\mu \mathrm{g} / \mathrm{kg})$, Inhibitor kappa B kinase inhibitor group (intrathecal injection of $50 \mu \mathrm{l} / \mathrm{kg}$ BMS-345541). Neuromotor function, pathological changes of spinal cord tissue, apoptosis rate of spinal cord tissue and changes of inflammatory factors were observed. The neuromotor function scores of rats in intrathecal group, intravenous group and intrathecal+intravenous group were significantly higher than those in model group at $24 \mathrm{~h}$ and $48 \mathrm{~h}$ after treatment $(\mathrm{p}<0.05)$ and those in intrathecal+intravenous group were significantly higher than those in intrathecal group at $24 \mathrm{~h}$ and $48 \mathrm{~h}$ after treatment, with statistical significance $(\mathbf{p}<\mathbf{0 . 0 5})$. In intrathecal group, vein group and intrathecal+vein group, the injury of nerve tissue structure was mild, the cells were slightly swollen and the cytoplasm was uniform. The apoptosis number of spinal cord injury tissue in intrathecal group, intravenous group and intrathecal+venous group was significantly lower than that of model group $(\mathbf{p}<\mathbf{0 . 0 5})$, and the apoptosis number of intrathecal+venous group was significantly lower than that of intrathecal group $(\mathbf{p}<\mathbf{0 . 0 5})$. The expression of interleukin-1 $\beta$, interleukin-6 and tumor necrosis factor- $\alpha$ messenger RNA in intrathecal group, intravenous group and intrathecal+venous group was significantly lower than that in model group $(p<0.05)$, while the mRNA expression of interleukin-1 $\beta$, interleukin-6 and tumor necrosis factor- $\alpha$ in intrathecal+venous group was significantly lower than that in intrathecal group $(\mathbf{p}<0.05)$. The expressions of inhibitor kappa $B$ kinase $\beta$, nuclear factor kappa-light-chain-enhancer of activated B cells messenger RNA and protein in the Inhibitor kappa B kinase $\beta$ inhibitor group and dexmedetomidine group were significantly lower than those in the model group $(p<0.05)$ and the expressions of inhibitor kappa $B$ kinase $\beta$, nuclear factor kappa-light-chainenhancer of activated $B$ cells messenger RNA and protein in the dexmedetomidine group were significantly lower than those in the inhibitor kappa $B$ kinase $\beta$ inhibitor group $(p<0.05)$. Intrathecal and intravenous dexmedetomidine can significantly improve the recovery of neuromotor function and reduce inflammatory response in rats with spinal cord injury. The mechanism may be related to the inhibition of inhibitor kappa B kinase/ nuclear factor kappa-light-chain-enhancer of activated B cells signaling pathway.

Key words: Injection route, spinal cord injury, dexmedetomidine, motor function, inflammatory response

Spinal cord injury is a serious disabling disease of the central nervous system. It is generally believed to be caused by primary injury and subsequent secondary injuries, and can occur in people of any age. According to statistics, the incidence of spinal cord injury in my country is about 6-7 per million people and it has been increasing year by year in recent years ${ }^{[1]}$. At present, the mechanism of spinal cord injury is still unclear, leading to unsatisfactory clinical treatment effects.
The secondary injury after spinal cord injury is a wellstudied injury mechanism. Including amino acid theory, vascular mechanism, electrolyte imbalance, apoptosis

This is an open access article distributed under the terms of the Creative Commons Attribution-NonCommercial-ShareAlike 3.0 License, which allows others to remix, tweak, and build upon the work non-commercially, as long as the author is credited and the new creations are licensed under the identical terms

Accepted 25 March 2021 Revised 10 January 2021 Received 15 October 2020

*Address for correspondence

E-mail: mitfykrx993@163.com 
theory, lipid peroxidation and free radical theory, etc., these theories have greatly enriched the understanding of the physiological matrix of spinal cord injury in this study ${ }^{[2,3]}$. Studies have confirmed that the immune inflammatory response caused by spinal cord injury can lead to neuronal apoptosis and further aggravate secondary spinal cord injury ${ }^{[4]}$. Therefore, finding a method that can inhibit secondary apoptosis of bone marrow nerve cells has become a hot spot in clinical research. Dexmedetomidine is a highly effective and highly selective $\alpha 2$ adrenergic receptor agonist. Its functions include sedation, anti-anxiety, analgesia, antisympathetic, etc. In clinical use, combined with other anesthetics can reduce the amount of other anesthetics and has a small effect on hemodynamics ${ }^{[5]}$. The main effect of dexmedetomidine on spinal nerves is to reduce the excitability of glutamate, inhibit the release of catecholamines, significantly improve the blood supply of neurons and regulate neuronal apoptosis. In addition to the protection of spinal cord neurons, dexmedetomidine has a significant inhibitory effect on the inflammatory response in the body, but there are few reports on whether it can treat spinal cord injury by inhibiting the inflammatory response ${ }^{[6]}$. This study established a rat spinal cord injury model to analyze the effects of dexmedetomidine administered by different injection routes on the recovery of rat motor function and alleviation of inflammation.

\section{MATERIALS AND METHODS}

\section{Experimental reagents and instruments:}

Dexmedetomidine Hydrochloride (Beijing Yita Biotechnology Co., Ltd.); Paraformaldehyde (Tianjin Institute of Chemical Reagents); PBS (Shanghai Guangrui Biotechnology Co., Ltd.); Rabbit antimouse Inhibitor kappa B kinase (IKK $\beta$ ), nuclear factor kappa-light-chain-enhancer of activated B cells (NF-kB) antibody (Dako Company, Denmark); antirabbit immunoglobulin (Xi' an Baiying Biotechnology Co., Ltd.); autoclave (Beijing Bomaixing Instrument Co., Ltd.); Ultra-pure water system (Beijing Zeping Technology Co., Ltd.); electronic analytical balance (Nanjing Beiden Medical Co., Ltd.); protein vertical electrophoresis system (Jiangsu Bomeida Life Science Co., Ltd.); Transfer tank (Beijing Yi Aobo Technology and Trade Co., Ltd.); ultra-low temperature refrigerator (ultra-low temperature refrigerator); micropipette (Plande (Shanghai) Trading Co., Ltd.).

\section{Establishment and grouping of experimental animal models:}

Forty eight healthy and clean male rats, aged 10-12 w, weighing $280 \pm 20 \mathrm{~g}$, were purchased from Beijing Weitonglihua Experimental Animal Co., Ltd. and raised in the animal experiment center of our hospital. The temperature is $24 \sim 26^{\circ}$, the light/darkness is $12 \mathrm{~h}$ each, free drinking and eating and the model is established after one week of adaptive feeding. The modified allen method was used to establish a rat model of random shock injury. The rats were anesthetized by intraperitoneal injection of $10 \%$ chloral hydrate, and the back was routinely prepared and disinfected. The $9^{\text {th }}$ thoracic vertebra was incised by $2 \mathrm{~cm}$. cut the deep fascia down along the tip of the spinous process, exposing the $10^{\text {th }}-12^{\text {th }}$ thoracic vertebrae and show the transverse process, and removes the $10^{\text {th }}-12^{\text {th }}$ thoracic spinous process and both sides of the lamina. Expose the spinal cord and use a $25 \mathrm{~g}, 2 \mathrm{~mm}$ diameter Korotkoff needle to freely fall from a $3 \mathrm{~cm}$ body to hit the spinal cord to establish an acute spinal cord injury model. The rats were divided into a control group: only surgical exposure and removal of the lamina, no spinal cord blow; model group: After the acute spinal cord injury model was established, the same amount of normal saline was given; intrathecal group: $3 \mu \mathrm{g} / \mathrm{kg}$ dexmedetomidine was injected intrathecally after modeling; intravenous group: After modeling, $3 \mu \mathrm{g} / \mathrm{kg}$ dexmedetomidine was injected into the femoral vein; intrathecal+intravenous group (dexmedetomidine group): After modeling, $3 \mu \mathrm{g} / \mathrm{kg}$ dexmedetomidine was injected intrathecal and femoral vein; IKK $\beta$ inhibitor group: $50 \mu \mathrm{l} / \mathrm{kg}$ BMS345541 was injected intrathecally.

\section{Detection method:}

Neuromotor function: The motor function of each group of rats was evaluated 1, 24 and $48 \mathrm{~h}$ after modeling with the Bassobiti motor function rating scale. The scale has a total score of 21 points, with 0 points representing complete paralysis and 21 points representing normal conditions.

Hematoxylin and eosin staining (HE staining): Take the spinal cord injury tissue section for HE staining, wash the section with double distilled water for 1 min after deparaffinization, stain with hematoxylin for $10 \mathrm{~min}$ and separate with $1 \%$ hydrochloric acid and alcohol for $1 \mathrm{~min}$. After washing with alkaline solution and promoting blue water, eosin was counterstained for $2 \mathrm{~min}$, dehydrated with gradient ethanol, 
transparent with xylene, sealed with neutral rubber and the morphological and structural changes of the spinal cord were observed under an optical microscope.

Terminal deoxynucleotidyl transferase dUTP nick end labeling (TUNEL) staining method: Take the spinal cord tissue and fix it with $10 \%$ formaldehyde solution to make routine pathological sections. After dewaxing with xylene, dehydrating with absolute ethanol, washing with $95 \%$ and $75 \%$ ethanol, TUNEL method is used to detect cell apoptosis. Fluorescence microscope was used to detect apoptotic cells and count the rate of positive cells.

Real-time quantitative Polymerase chain reaction (PCR) method to detect related gene expression: Trizol method was used to extract total RNA from rat spinal cord injury tissues in each group, and determine the content and integrity; The diluted RNA sample is reverse transcribed, and the mRNA is quantitatively analyzed by real-time quantitative PCR. After the reaction is completed, the prepared cDNA is subjected to PCR amplification. Use Glyceraldehyde 3-phosphate dehydrogenase (GAPDH) as an internal reference gene to obtain the $\mathrm{Ct}$ value of each target gene. Reaction conditions: $95^{\circ}$ and pre-denaturation for $10 \mathrm{~min}, 95^{\circ}$ for $15 \mathrm{~s}, 60^{\circ}$ for $45 \mathrm{~s}, 72^{\circ}$ extension for $2 \mathrm{~min}, 40$ cycles, $4^{\circ}$ storage, relative quantification of each gene data (data analysis with the $2^{-\Delta \Delta \mathrm{CT}}$ formula).

Western blot method to detect the expression of related proteins: Add Radioimmunoprecipitation assay (RIPA) lysate containing protease inhibitor and phosphatase inhibitor phenylmethylsulfonyl fluoride (PMSF) to the spinal cord tissue and prepare the working solution according to the bicinchoninic acid assay kit (BCA kit) for protein quantification. $30 \mu \mathrm{g}$ protein and $4 \times$ loading buffer were mixed and centrifuged to obtain the supernatant, separated by sodium dodecyl sulphate -polyacrylamide gel electrophoresis, and transferred to polyvinylidene fluoride (PVDF) membrane. $10 \mathrm{ml}$ of $5 \%$ skimmed milk powder was blocked at room temperature for $2 \mathrm{~h}$ or incubated overnight at $4^{\circ}$. After incubating the PVDF membrane with the primary antibody IKK $\beta$ and $N F-\kappa B$, incubate overnight in a refrigerator at $4^{\circ}$. Add the corresponding secondary antibody and incubate for $1 \sim 2 \mathrm{~h}$ at room temperature and develop the color by Enhanced chemiluminescence (ECL) method.

\section{Statistical methods:}

The data in this study were analyzed by SPSS21.0 software package, and the measurement data were all expressed by $(\overline{\mathrm{x}} \pm \mathrm{s})$ and the comparison of the two groups was seen by t-test. A one-way analysis of variance was used to compare data between multiple groups and $\mathrm{p}<0.05$ was regarded as statistically significant.

\section{RESULTS AND DISCUSSION}

The neuromotor function scores of rats in the intrathecal group, intravenous group and intrathecal+intravenous group were significantly higher than those in the model group during the treatment of spinal cord injury at $24 \mathrm{~h}$ and $48 \mathrm{~h}(\mathrm{p}<0.05)$. The neuromotor function scores of rats in the intrathecal+vein group were significantly higher than those in the intrathecal group at $24 \mathrm{~h}$ and $48 \mathrm{~h}$ after treatment, and the difference was statistically significant $(\mathrm{p}<0.05)($ Table 1$)$.

The results of HE staining showed that the spinal cord structure of the control group was normal, with clear and complete neuron outlines and deep cytoplasmic staining. In the model group, a large number of neurons were edema and necrosis, gray matter vacuoles were formed, inflammatory cells were infiltrated, and nuclei were pyknotic. Compared with the model group, the nerve tissue structure of the intrathecal group, the vein group and the intrathecal+vein group was less damaged, the cells were slightly swollen and the cytoplasm was uniform. The degree of spinal cord injury in the intrathecal+vein group was less than that of the above

TABLE 1: EFFECTS OF DEXMEDETOMIDINE ON NEUROMOTOR FUNCTION IN RATS WITH SPINAL CORD INJURY ( $\overline{\mathbf{x}} \pm \mathbf{s})$

\begin{tabular}{lcccc}
\hline Group & Number of samples & $1 \mathrm{~h}$ & $24 \mathrm{~h}$ & $48 \mathrm{~h}$ \\
\hline Control group & 8 & $17.60 \pm 1.10$ & $19.67 \pm 1.51$ & $20.13 \pm 1.61$ \\
Model group & 8 & $0.13 \pm 0.04^{*}$ & $0.22 \pm 0.06^{*}$ & $0.26 \pm 0.02^{*}$ \\
Intrathecal group & 8 & $0.15 \pm 0.02^{*}$ & $3.55 \pm 0.46^{* \#}$ & $7.30 \pm 0.81^{* \#}$ \\
Intravenous group & 8 & $0.15 \pm 0.04^{*}$ & $3.14 \pm 0.86^{* \#}$ & $7.15 \pm 1.12^{* \#}$ \\
Intrathecal+vein group & 8 & $0.17 \pm 0.03^{*}$ & $7.65 \pm 0.72^{* \# \Delta}$ & $12.13 \pm 1.02^{* \# \Delta}$ \\
F & & 2005.79 & 622.39 & 388.93 \\
P & & $<0.001$ & $<0.001$ & $<0.001$ \\
\hline
\end{tabular}

Note: Compared with the control group ${ }^{*} \mathrm{p}<0.05$; compared with the model group ${ }^{*} \mathrm{p}<0.05$; compared with the intrathecal group ${ }^{\triangle} \mathrm{p}<0.05$ 
two groups (fig. 1).

The results of TUNEL staining method showed that in the $24 \mathrm{~h}$ and $48 \mathrm{~h}$ model group, intrathecal group, vein group, and intrathecal+vein group of spinal cord injury, the number of cell apoptosis in spinal cord injury was significantly higher than that in the control group $(\mathrm{p}<0.05)$. The number of apoptosis in spinal cord injury tissues in the intrathecal group, vein group, and intrathecal+vein group was significantly lower than that of the model group $(p<0.05)$ and the number of apoptosis in the intrathecal+vein group was significantly lower than that in the intrathecal group $(\mathrm{p}<0.05)$ (Table 2).

The expression levels of Interleukin-1 $\beta$ (IL-1 $\beta$ ), Interleukin-6 (IL-6) and Tumor Necrosis Factor- $\alpha$ (TNF- $\alpha$ ) messenger RNA (mRNA) in spinal cord injury tissues in the model group, intrathecal group, vein group, and intrathecal+vein group were significantly higher than those in the control group $(p<0.05)$. The expression of IL- $1 \beta$, IL- 6 and TNF- $\alpha$ mRNA in spinal cord injury tissues in the intrathecal group, vein group, and intrathecal+vein group were significantly lower than those in the model group $(\mathrm{p}<0.05)$. The expression of IL- $1 \beta$, IL- 6 and TNF- $\alpha$ mRNA in the intrathecal+vein group was significantly lower than that in the intrathecal group ( $<<0.05)$ (Table 3$)$.

The expression of IKK $\beta$ and NF- $\mathrm{KB}$ mRNA and protein in the spinal cord injury tissue of the model group was significantly higher than that of the control group $(\mathrm{p}<0.05)$. The mRNA and protein expressions of IKK $\beta$ and NF- $\kappa B$ in spinal cord injury tissues in the IKK $\beta$ inhibitor group and dexmedetomidine group were significantly lower than those in the model group $(\mathrm{p}<0.05)$. The expressions of IKK $\beta$ and NF$\kappa \mathrm{B}$ mRNA and protein in spinal cord injury tissues in the dexmedetomidine group were significantly lower than those in the IKK $\beta$ inhibitor group $(\mathrm{p}<0.05)$ (fig. 2 and fig. 3).

Dexmedetomidine is the dextrorotatory isomer of the racemic mixture of medetomidine. It has attracted the attention of scholars because of its good sedative effect. In addition, it can also relieve pain, anti-anxiety and inhibit sympathetic nerve activity. Stable perioperative hemodynamics, etc., as an anesthesia adjuvant, has been widely used in clinical anesthesia and intensive care ${ }^{[7]}$. In recent years, animal experiments and clinical studies have found that dexmedetomidine also has a certain neuroprotective effect and it can also protect spinal cord
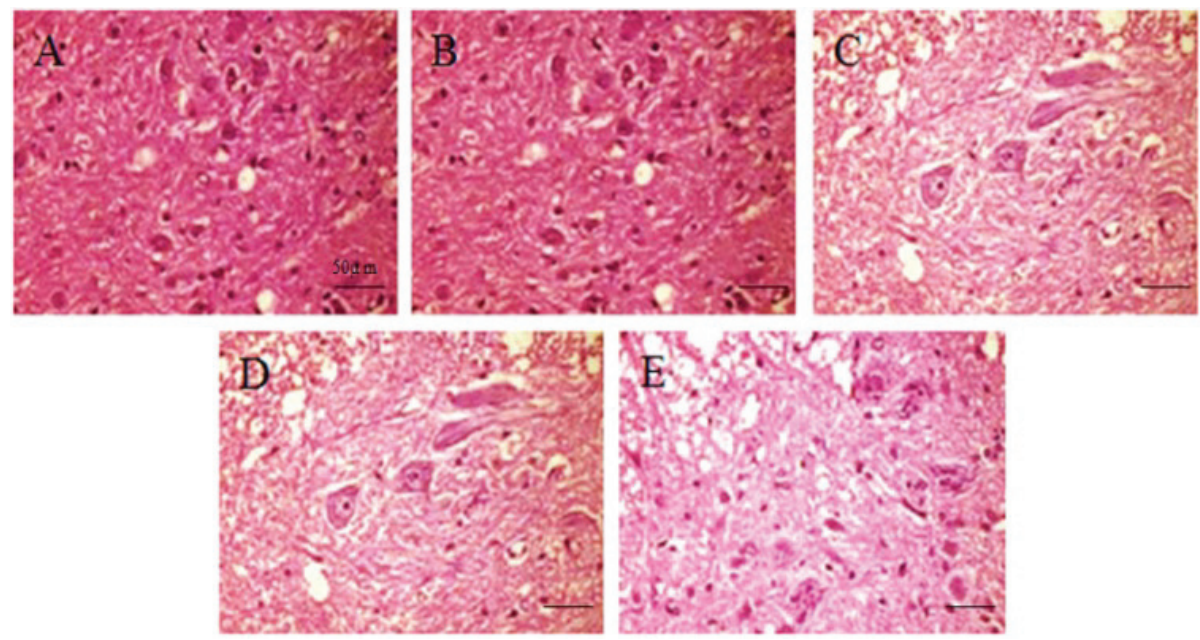

Fig. 1: HE staining method to observe the effect of dexmedetomidine on the pathological changes of spinal cord $(\times 400)$ A: Control group B: Model group C: Intrathecal group D: Intravenous group E: Intrathecal+intravenous group

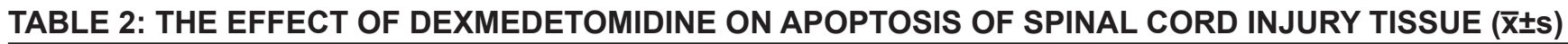

\begin{tabular}{lcccc}
\hline Group & Number of samples & $1 \mathrm{~h}$ & $24 \mathrm{~h}$ & $48 \mathrm{~h}$ \\
\hline Control group & 8 & $7.18 \pm 0.25$ & $6.94 \pm 0.35$ & $6.49 \pm 0.55$ \\
Model group & 8 & $7.27 \pm 0.56$ & $25.21 \pm 1.54^{*}$ & $35.26 \pm 1.46$ \\
Intrathecal group & 8 & $7.38 \pm 0.24$ & $17.46 \pm 1.31^{\text {*\# }}$ & $25.19 \pm 1.57^{\text {*\# }}$ \\
Intravenous group & 8 & $7.22 \pm 0.75$ & $17.26 \pm 1.41^{\text {*\# }}$ & $25.17 \pm 1.30^{\text {*\# }}$ \\
Intrathecal + vein group & 8 & $7.33 \pm 0.49$ & $11.47 \pm 1.16^{\text {*\# }}$ & $15.06 \pm 1.31^{\text {*\# }}$ \\
F & & 0.21 & 252.65 & 581.78 \\
p & & 0.930 & $<0.001$ & $<0.001$ \\
\hline
\end{tabular}

Note: Compared with the control group ${ }^{*} \mathrm{p}<0.05$; compared with the model group ${ }^{*} \mathrm{p}<0.05$; compared with the intrathecal group ${ }^{\triangle} \mathrm{p}<0.05$ 
TABLE 3: THE EFFECT OF DEXMEDETOMIDINE ON INFLAMMATORY FACTORS IN SPINAL CORD INJURY

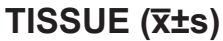

\begin{tabular}{lcccc}
\hline Group & Number of samples & IL-1B mRNA & IL-6 mRNA & TNF-a mRNA \\
\hline Control group & 8 & $0.17 \pm 0.01$ & $0.46 \pm 0.04$ & $0.38 \pm 0.02$ \\
Model group & 8 & $1.14 \pm 0.02^{*}$ & $1.21 \pm 0.05^{*}$ & $1.23 \pm 0.10^{*}$ \\
Intrathecal group & 8 & $0.83 \pm 0.09^{* \#}$ & $0.96 \pm 0.07^{\text {*\# }}$ & $0.91 \pm 0.03^{* \#}$ \\
Intravenous group & 8 & $0.82 \pm 0.08^{* \#}$ & $1.01 \pm 0.08^{* \#}$ & $0.90 \pm 0.21^{\text {*\# }}$ \\
Intrathecal + vein & 8 & $0.50 \pm 0.04^{* \# \Delta}$ & $0.71 \pm 0.07^{* \# \Delta}$ & $0.67 \pm 0.02^{* \# \Delta}$ \\
group & & 976.80 & 166.01 & 71.45 \\
F & & $<0.001$ & $<0.001$ & $<0.001$ \\
p & & & \\
\hline
\end{tabular}

Note: Compared with the control group ${ }^{*} \mathrm{p}<0.05$; compared with the model group ${ }^{\#} \mathrm{p}<0.05$; compared with the intrathecal group ${ }^{\Delta} \mathrm{p}<0.05$

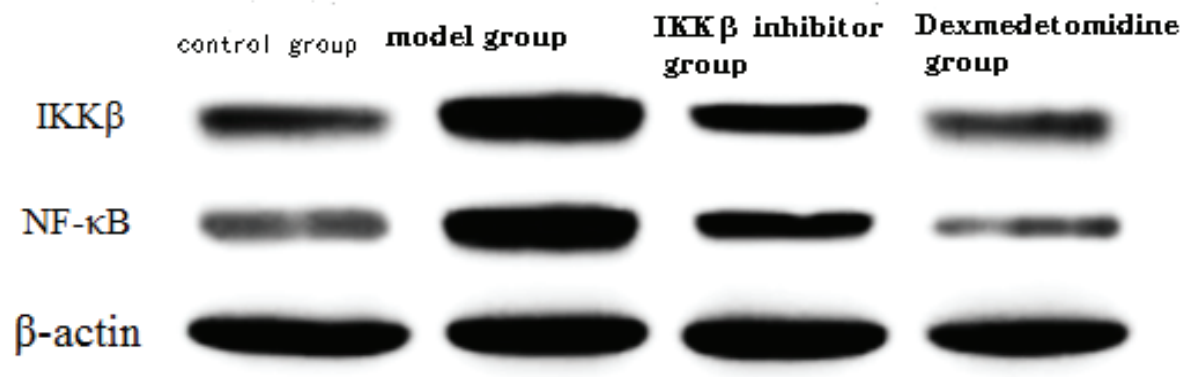

Fig. 2: Western blot method to detect the protein expression of IKK $\beta$ and NF- $\kappa B$ in each group
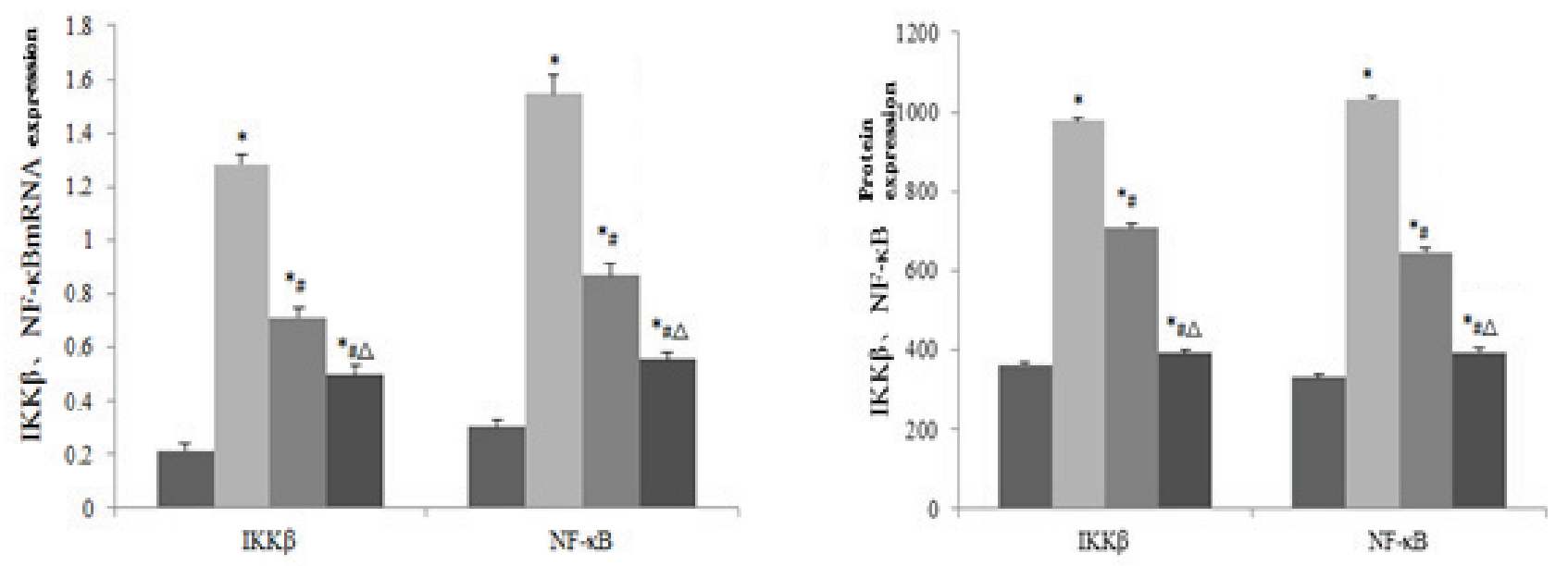

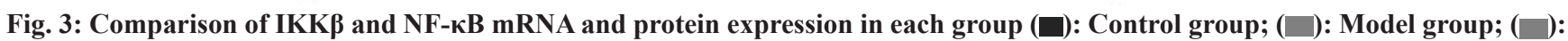
IKK $\beta$ inhibitor group; (ם): Dexmedetomidine group

Note: Compared with the control group * $\mathbf{p}<0.05$; compared with the model group ${ }^{*} \mathbf{p}<0.05$; compared with the IKK $\beta$ inhibitor group ${ }^{\Delta} \mathbf{p}<\mathbf{0 . 0 5}$

ischemia-reperfusion injury ${ }^{[8]}$. Related studies have shown that intraperitoneal injection of dexmedetomidine in New Zealand rabbits with traumatic spinal cord injury can significantly inhibit lipid peroxidation. Enhance the activity of the endogenous antioxidant system, thereby improving nerve function and protecting spinal cord ischemic injury ${ }^{[9]}$. In addition to directly protecting the spinal cord nerves, dexmedetomidine can also protect the nervous system by inhibiting the body's inflammatory response. It can inhibit sympathetic nerve excitement by activating the central $\alpha 2$ receptor, and reduce the level of inflammatory factors and inhibit the inflammatory response ${ }^{[10]}$. Some scholars have found through research that giving high-dose dexmedetomidine to patients with spinal cord injury can significantly reduce the content of chemokines in the lungs and reduce the tissue infiltration of neutrophils, and the effect is significant ${ }^{[11,12]}$. This study established a spinal cord injury model and observed the neuromotor function of rats. It was found that the neuromotor function scores of rats in the intrathecal, intravenous and intrathecal+intravenous groups were 
significantly higher than those in the model group $(p<0.05)$. The neuromotor function scores of rats in the intrathecal+vein group were significantly higher than those in the intrathecal group at $24 \mathrm{~h}$ and $48 \mathrm{~h}(\mathrm{p}<0.05)$. In addition, the nerve tissue structure of the intrathecal group, the vein group and the intrathecal+vein group was slightly damaged, the cells were slightly swollen, and the cytoplasm was uniform. The degree of spinal cord injury in the intrathecal+vein group was less than that of the above two groups. From the above results, it can be seen that intrathecal+intravenous injection of dexmedetomidine is significantly better than single route administration in restoring spinal cord injury and neuromotor function.

A large number of studies have found that inflammatory cytokines can aggravate the degree of secondary spinal cord injury, mainly because a large number of neutrophils are produced after spinal cord injury to gather at the injury site. It also releases elastase and oxygen free radicals, which damage the integrity of the vascular endothelium, thereby promoting the deterioration of nerve function ${ }^{[13,14]}$. In this study, we found that the expression levels of IL-1 $\beta$, IL-6, and TNF- $\alpha$ mRNA in the spinal cord injury tissue of the intrathecal group, vein group, and intrathecal+vein group were significantly lower than those in the model group at $48 \mathrm{~h}$ after spinal cord injury treatment $(\mathrm{p}<0.05)$. The expression of IL-1 $\beta$, IL- 6 and TNF- $\alpha$ mRNA in the intrathecal+vein group was significantly lower than that in the intrathecal group $(\mathrm{p}<0.05)$. It can be seen that dexmedetomidine administered by different routes of administration can effectively inhibit the expression of inflammatory factors related to spinal cord injury, and the level of inflammatory factors administered by intrathecal+intravenous injection is the lowest.

In the process of spinal cord injury, NF- $\kappa \mathrm{B}$ plays a very important role as a key regulator of inflammatory gene expression. Its main function is to regulate the inflammatory response of memory, and has a certain impact on cell proliferation and survival. IKK $\beta$ plays an important role in the activation process of NF- $\kappa B$, and can realize the regulation of NF- $\kappa \mathrm{B}$-dependent gene transcription process ${ }^{[15-16]}$. The results of this study showed that the IKK $\beta$ and NF- $\mathrm{BB}$ mRNA and protein expressions in the spinal cord injury tissues of the IKK $\beta$ inhibitor group and dexmedetomidine group were significantly lower than those of the model group $(\mathrm{p}<0.05)$. The expressions of IKK $\beta$ and NF$\kappa \mathrm{B}$ mRNA and protein in spinal cord injury tissues in the dexmedetomidine group were significantly lower than those in the IKK $\beta$ inhibitor group $(p<0.05)$. It can be seen that dexmedetomidine can reduce the inflammatory response after spinal cord injury by inhibiting the IKK $\beta / \mathrm{NF}-\kappa \mathrm{B}$ signaling pathway, thereby playing a neuroprotective function.

In summary, intrathecal+intravenous injection of dexmedetomidine has a more significant effect on spinal cord injury rats than a single route. It can obviously promote the recovery of neuromotor function in rats and reduce inflammation. The related mechanism may be related to the inhibition of IKK $\beta / \mathrm{NF}-\mathrm{kB}$ signaling pathway.

\section{Ethical approval:}

This study was reviewed and approved by the Ethics Committee for Experimental Animals of First People's Hospital of Jinan City (ID:FP32105) and all mice were treated according to the guidelines of principles of laboratory animal care (NIH publication No. 86-23, revised 1985).

\section{REFERENCES}

1. Badhiwala JH, Ahuja CS, Fehlings MG. Time is spine: a review of translational advances in spinal cord injury. J Neurosurg Spine 2018;30(1):1-18.

2. Silva NA, Salgado AJ, Sousa RA, Oliveira JT, Pedro AJ, LeiteAlmeida H, et al. Development and characterization of a novel hybrid tissue engineering-based scaffold for spinal cord injury repair. Tissue Eng Part A 2018;16(1):45-54.

3. Nathan F, Li S. Environmental cues determine the fate of astrocytes after spinal cord injury. Neural Regen Res 2017;12(12):1964-70.

4. Burns AS, Marino RJ, Kalsi-Ryan S, Middleton JW, Tetreault LA, Dettori JR, et al. Type and Timing of Rehabilitation Following Acute and Subacute Spinal Cord Injury: A Systematic Review. Global Spine J 2017;7(3):175-94.

5. Weerink MA, Struys MM, Hannivoort LN, Barends CR, Absalom AR, Colin P. Clinical pharmacokinetics and pharmacodynamics of dexmedetomidine. Clin Pharmacokinet 2017;56(8):893-913.

6. Farooq N, Singh RB, Sarkar A, Rasheed MA, Choubey S. To Evaluate the Efficacy of Fentanyl and Dexmedetomidine as Adjuvant to Ropivacaine in Brachial Plexus Block: A Doubleblind, Prospective, Randomized Study. Anesth Essays Res 2017;11(3):730-9.

7. Lavon H, Matzner P, Benbenishty A, Sorski L, Rossene E, Haldar $\mathrm{R}$, et al. Dexmedetomidine promotes metastasis in rodent models of breast, lung, and colon cancers. Br J Anaesth 2018;120(1):188-96.

8. Gupta B, Verma RK, Kumar S, Chaudhary G. Comparison of Analgesic Efficacy of Dexmedetomidine and Midazolam as Adjuncts to Lignocaine for Intravenous Regional Anesthesia. Anesth Essays Res 2017;11(1):62-73.

9. Noh C, Ko YK, Kim YH, Lim CS, Chung WS, Lee JY, et al. Effect of dexmedetomidine on endotracheal intubating 
conditions during endotracheal intubation without neuromuscular blocker following propofol/remifentanil. Anesth Pain Med 2017;12(1):56-61.

10. Modir H, Yazdi B, Talebi H, Eraghi MG, Behrouzi A, Modir A. Analgesic effects of ketorolac/lidocaine compared to dexmedetomidine/lidocaine in intravenous regional anesthesia. Ann Trop Med Public Health 2017;10(3):1-5.

11. Mahmoud M, Ishman SL, Mcconnell K, Fleck R, Shott S, Mylavarapu G, et al. Upper Airway Reflexes are Preserved During Dexmedetomidine Sedation in Children With Down Syndrome and Obstructive Sleep Apnea. J Clin Sleep Med 2017;13(5):721-7.

12. Singh S, Prasad C. Post-operative analgesic effect of dexmedetomidine administration in wound infiltration for abdominal hysterectomy: A randomised control study. Indian J Anaesth 2017;61(6):494-8.
13. Wang YH, Chen J, Zhou J, Nong F, Lv JH, Liu J. Reduced inflammatory cell recruitment and tissue damage in spinal cord injury by acellular spinal cord scaffold seeded with mesenchymal stem cells. Exp Ther Med 2017;13(1):203-7.

14. Akbari M, Khaksari M, Rezaeezadeh-Roukerd M, Mirzaee M, Nazari-Robati M. Effect of chondroitinase $\mathrm{ABC}$ on inflammatory and oxidative response following spinal cord injury. Iran J Basic Med Sci 2017;20(7):806-12.

15. Douglass JD, Dorfman MD, Fasnacht R, Shaffer LD, Thaler JP. Astrocyte IKK $\beta / \mathrm{NF}-\kappa \mathrm{B}$ signaling is required for dietinduced obesity and hypothalamic inflammation. Mol Metab 2017;6(4):366-73.

16. Cho JM, Yun SM, Choi YH, Heo J, Kim NJ, Kim SH, et al. Xanthohumol prevents dextran sulfate sodium-induced colitis via inhibition of $\mathrm{IKK} \beta / \mathrm{NF}-\kappa \mathrm{B}$ signaling in mice. Oncotarget 2017;9(1):866-80. 